Revista Iberoamericana, Vol. LXXVII, Núm. 235, Abril-Junio 2011, 525-537

\title{
PAISAJES INTERIORES Y EL MUNDO CUÁNTICO EN LA POESÍA DE NANCY MOREJÓN
}

POR

\author{
GWENDOLYN Díaz \\ St. Mary's University
}

The coming together of our insights about
the world around us and the world inside us
is a satisfying feature of the recent evolution
of science.
Ilya Prigogine
We live our lives inscrutably included within
the streaming mutual life of the universe.
Martin Buber
En el centro del mundo
caen las redes
y los peces aullan
durante el plenilunio.
Nancy Morejón, "Redes"

Lo que interesa acá es explorar el retrato interior del sujeto, en este caso el femenino, que traza la poesía de Nancy Morejón. Esta obra dibuja un "yo” femenino desde el interior de la subjetividad, enlazándolo al mismo tiempo con el paisaje exterior. Se produce una fusión tanto metonímica como metafórica del sujeto con la naturaleza. Pero esta simbiosis entre mujer y naturaleza no se hace desde la tradicional perspectiva de género, sino desde una visión íntimamente conocedora de la conexión del sujeto consciente con el universo físico. Es allí donde se establece la relación con la física cuántica, o sea el estudio de la relación o en términos cuánticos la conectividad de todos los elementos del mundo físico, desde la conciencia humana y sus procesos cerebrales, hasta los átomos más remotos del universo. El estudio de la relación entre la física y las humanidades no es algo nuevo (Prigogine 289). Ilya Prigogine, premio Nobel en termodinámica de 1977, utilizó sus descubrimientos científicos para demostrar que esos mismos principios afectan a la psicología y el comportamiento del ser humano y su sociedad. Es decir, el campo de las humanidades y el de las ciencias 
tienen un diálogo mutuo. La poesía es uno de los foros en el cual se da este diálogo.

Con la sabiduría intuitiva del poeta, Nancy Morejón evoca la fusión de la conciencia del sujeto con el mundo natural del tiempo y del espacio, para crear así una obra poética donde el ser humano se integra con el mundo físico que lo rodea. Este trabajo sostiene que la poética de Morejón revela una visión cuántica del universo, un universo donde el ser humano, en cuanto ente físico y psíquico al mismo tiempo, participa del ritmo vital de la existencia universal compartida. Esta visión cuántica del mundo se encuentra en oposición a la visión tradicional del mundo moderno, formado por los preceptos de la física newtoniana y la filosofía cartesiana de cuerpos autónomos y separados. La visión tradicional del mundo es una visión dualista; una de separación y oposiciones que divide al mundo físico del espiritual, divide al sujeto del objeto y al ser humano de la naturaleza. Ésta es la visión científica y filosófica que ha formado al mundo moderno y que ha llevado al sentimiento de alienación del ser humano, tan visto por los poetas de fin de siglo y los existencialistas, y cada vez más obvio en el transcurrir de la postmodernidad. La visión cuántica niega el dualismo de Newton, Descartes, Santo Tomás de Aquino y otros. No divide al sujeto humano en dos, cuerpo contra espíritu, hombre contra naturaleza, consciente contra inconsciente. Lo que aprendemos de la física cuántica es que todo lo que está vivo está en una relación de interconexión. Todo lo que vive emite energía y los campos energéticos se entrelazan entre sí. Por ende, todo está en un constante flujo de energías y de cambios a los cuales se llega por medio de la creatividad y la libertad de elección (Zohar 178). Similar a la teoría de la evolución darwiniana, hay una multiplicidad de posibilidades y el sujeto elige una de ellas, determinando así la dirección del camino o el cauce de la bifurcación (pensemos en Borges) del proceso. ${ }^{1}$ Esta libertad es lo que lleva a la creatividad y, según la cuántica, la razón de ser del ser humano es crear en su relación con sus semejantes y el universo.

La visión cuántica de la relación y conexión entre todas las cosas no es un concepto nuevo para los poetas que han sabido interpretar el universo desde una sabiduría intuitiva y relacional, ni tampoco para los filósofos y los teólogos del oriente. Pensemos en el Tao que enseña la unidad y el equilibrio de todo ser con la naturaleza, la unidad del sujeto con el objeto. El budismo, por ejemplo, transciende la idea de un Dios personal dando preferencia a una divinidad cósmica. La meta es la armonía de todas las cosas. De allí que el filósofo hindú Krishnamurti concluyera: "I am the world” ("Yo soy el mundo"), frase que viene a ser una rendición poética de la visión

1 Lo interesante y lo que demuestra la teoría del caos es que todo sistema tiende a organizarse con cierto orden que apunta a una dirección dada o a una coherencia existencial vista por los teóricos del caos. Ver James Gleick, Chaos. Making a New Science. La referencia a Borges apunta particularmente al cuento “El jardín de los senderos que se bifurcan” donde Borges prefigura el fenómeno caótico.

Revista Iberoamericana, Vol. LXXVII, Núm. 235, Abril-Junio 2011, $525-537$
ISSN 2154-4794 (Electrónico) 
cuántica (177). Un ser humano concebido como ente independiente y separado de lo que lo rodea no se responsabiliza por el mundo que considera ajeno, por el otro, por lo otro. Al contrario, se dedica a explotar a la naturaleza o a dominar a sus semejantes. Es así como hemos llegado a los problemas ambientales y ecológicos que amenazan el futuro del planeta.

La física cuántica conlleva una perspectiva revolucionaria sobre la relación de todo lo viviente y esta visión se ve expresada en la poesía de Nancy Morejón, donde el sujeto humano está en diálogo con el mundo natural, con su semejante, con las fuerzas del cosmos, con los objetos más mínimos y los sentimientos más profundos. Revela una conciencia atenta y en relación integral con todos los aspectos del mundo que la rodea: el viento, el mar, los pájaros, las personas, el dolor, la injusticia, la belleza, las estrellas, un patio, una madre, la arena, todo lo que interactúa con la conciencia del sujeto poético se incorpora al yo poético, en una especie de fusión con el otro y lo otro. Este mundo poético revela la cualidad de conectividad, un fenómeno que se explica en términos cuánticos por las ondas energéticas que emiten los electrones. Todo lo vivo está compuesto por átomos y electrones. Los electrones se expresan de dos formas, como partículas y como ondas. Las partículas corresponden a la individualidad, mientras que la función onda las relaciona e interconecta como unidad de electrones (Zohar 25). Un ejemplo sería percibir una ola de mar como ola o como una serie infinita de moléculas de agua. Es justamente esta cualidad dual del electrón que caracteriza todo lo vivo. Es individual y colectivo a la vez, tanto a nivel molecular como al humano y al cosmológico. Y es precisamente esta conectividad lo que caracteriza la poesía de Morejón. Veamos a continuación los siguientes poemas.

En el poema "Redes" de Morejón se da un interesante juego de redes que ondulan por los espacios terrenales, abarcando en sus fibras a todo tipo de ser, desde los peces, al árbol, el mar, el polvo, la hierba y también a una bailarina.

\author{
En el centro del mundo \\ caen las redes \\ y los peces aúllan \\ durante el plenilunio. \\ La bailarina \\ entre las redes. \\ Redes opacas \\ como troncos. \\ Redes inmarcesibles. \\ Y las sales del mar \\ pululando en la luz. (270)
}

ISSN 0034-9631 (Impreso) 
Esta serie de imágenes de redes refleja la teoría de cuerdas relacionada con la física cuántica, según la cual el universo está unido por una imperceptible red de cuerdas que sirve de base y unión de todo lo que existe y que al mismo tiempo permite la conectividad o el aspecto onda de las partículas de todo lo viviente. ${ }^{2}$

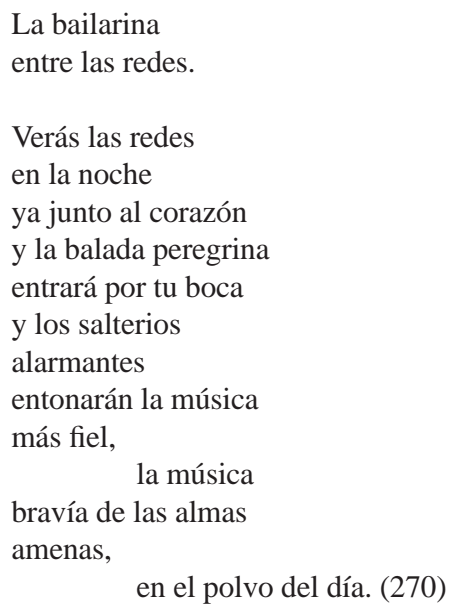

Al final del poema se repite la imagen inicial de las redes que caen sobre el mundo envolviendo a la bailarina entre sus cuerdas.

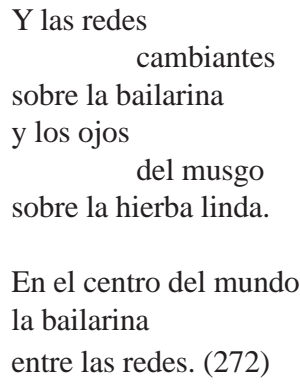

Es de notar que el poema encierra otras interpretaciones, particularmente por su carácter sensual. Pero la analogía entre la naturaleza y la red invisible de conectividad que entreteje todo lo existente se comprueba por el empleo de términos que crean imágenes cosmológicas: "el centro del mundo", "el plenilunio", "el mar”, "la luz

\footnotetext{
2 Ver Greene.
}

ISSN 0034-9631 (Impreso) 
que pulula”, "el polvo de la tierra”, “el desierto” y finalmente lo más específico: "la hierba”, "el musgo" y "la bailarina”. Sobre cada uno de estos cae esa red unificadora. Y la bailarina no se escapa, no está separada de los fenómenos de la naturaleza sino que es uno de ellos. Por eso la repetición eficaz de que la bailarina se encuentra también "entre las redes". Las redes del poema reflejan en forma figurativa la teoría de cuerdas, o sea la interconectividad o red cósmica que une a la naturaleza, el sujeto y el universo.

El poema "Ritornello" ilustra esta conexión por medio de la figura poética de la sinestesia. La sinestesia, tan característica de los poetas franceses simbolistas, es la mezcla o intercambio de sensaciones -visuales, auditivas, olfativas, gustativas, táctilesentre sí, y entre éstas y las emociones. Este concepto proviene de la synaesthesis que es una sensación de totalidad e integridad. Al releer a los simbolistas comprendemos que esta forma de percibir el mundo no se descubre sólo en la física cuántica, sino también en la poesía y la filosofía. Baudelaire introduce el concepto de la interconectividad de los sentidos y las emociones humanas en su famoso poema "Correspondances", donde se refiere a este fenómeno como "long échos qui de loin se confondent/ Dans une ténébreuse et profonde unité” [... ecos que desde lejos se confunden/ En una tenebrosa y profunda unidad] (33).

En el caso de Morejón, la poeta lleva esa unidad de experiencia un paso más allá. Veamos el poema "Ritornello".

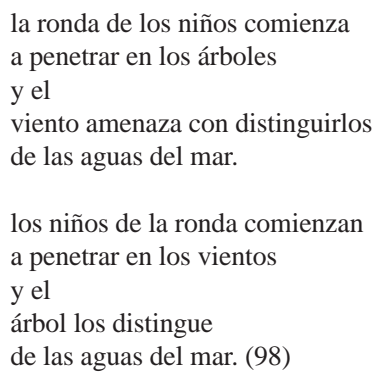

La poeta sugiere una relación sinestésica entre unos niños, los árboles, el viento y las aguas del mar. La imagen de una ronda de niños que "penetra" adentro de los árboles es incongrua. La acción de penetrar pertenece al viento, pero aquí el viento "distingue", un acto humano, a los niños de las aguas del mar. En la segunda estrofa los niños de la ronda "penetran" los vientos y es el "árbol" quien distingue ahora a los niños.

Se produce aquí lo que en términos cuánticos se denomina superposición, la capacidad que tienen los electrones de ocupar un mismo espacio al mismo tiempo (el electrón onda). Es una fusión que no podemos percibir con nuestros sentidos, pero que

Revista Iberoamericana, Vol. LXXVII, Núm. 235, Abril-Junio 2011, $525-537$
ISSN 2154-4794 (Electrónico) 
da lugar a lo que se llama el salto cuántico, o sea la capacidad de ser una partícula y una onda al mismo tiempo, de estar en dos lugares al mismo tiempo (Zohar 30). Este fenómeno físico lleva a una nueva conceptualización del tiempo y el espacio más allá de los descubrimientos de Einstein. Y, como los descubrimientos de Einstein, la física cuántica ha contribuido a formar una nueva visión del mundo.

El poema "Impresiones" ofrece otra perspectiva sobre la correlatividad del tiempo y del espacio. La visión cuántica del tiempo y el espacio como una sincronía donde todo sucede al mismo tiempo es lo mismo que negar la flecha del tiempo y establecer la perspectiva de la atemporalidad (Prigogine 229-30). A nivel cuántico el tiempo y el espacio se unen en lo que los científicos denominan el espacio de fases, donde todo existe en un estado de interconexión (Briggs y Peat 32). En el primero de sus Quartets (Cuartetos), el poeta modernista T. S. Eliot expresó este concepto así: "Time past and time future are both perhaps present in time now” (13, la traducción es mía). De forma similar, como el poema "Impresiones" de Morejón expresa el concepto de sincronía creando una imagen donde el espacio y el tiempo parecen girar como un todo indisoluble y donde el ser humano se confunde con el fluir eterno del universo.

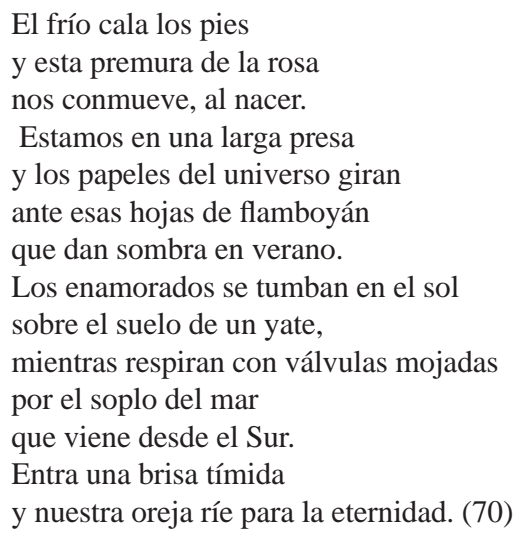

Esos papeles del universo que giran alrededor de los enamorados tumbados al sol connotan un despertar al conocimiento universal, el nacer para apreciar la premura de la rosa y el frío de los pies, el soplo del mar y la brisa que entra para que nuestra oreja ría "para la eternidad”. La poeta yuxtapone aquí la singularidad del individuo con la eternidad del universo, sugiriendo con la figura sinestésica "nuestra oreja que ríe para la eternidad" que la conciencia del individuo también es atemporal. Pies, rosa, brisa, sol, mar, sujeto, amor, son todos parte del fluir del universo. Cuando comienza el poema el sujeto está atrapado en una "presa", la presa de sus limitaciones de percepción. Pero

Revista Iberoamericana, Vol. LXXVII, Núm. 235, Abril-Junio 2011, $525-537$
ISSN 2154-4794 (Electrónico) 
al dejarse llevar por los "papeles del universo que giran" en su derredor, o sea por la sabia dinámica del universo, es entonces cuando su oreja siente las vibraciones que lo conectan a la eternidad. "Ríe" porque está en una relación armónica, en sincronía con la creación. Es acertada esta sinestesia porque el sonido se transmite por medio de vibraciones, ondas de sonido, o sea, la imagen auditiva se fusiona con la emocional y resulta en una epifanía de eternidad; en términos cuánticos, todo lo vivo vibra en la contigüidad sincrónica del tiempo-espacio (Zohar 36-37).

Sigamos con el concepto de las vibraciones al aproximarnos al poema "El tambor". La cualidad rítmica del poema convoca la onda del sonido que vibra y nos penetra. Las ondas de sonido del tambor se unen al cuerpo de la voz poética cuya energía también emite ondas. Hay una conjugación de las vibraciones del tambor con las del cuerpo que late con la energía que transmite su aura. El aura no es más que el campo electromagnético que se desprende de nuestro cuerpo y que sólo deja de existir en el momento de la muerte. Vida es vibración, es conexión es formar parte del ritmo armonioso del mundo palpitante. ${ }^{3}$ Tanto en su imagen auditiva como en lo conceptual el poema "Tambor" transmite el efecto de las vibraciones sincrónicas del universo. Cuando nuestra conciencia, nuestro cuerpo, nuestra subjetividad está a tono (nótese la expresión “estar a tono") con lo que lo rodea, el resultado es el equilibrio y la iluminación, como sugiere en el poema "El tambor".

Mi cuerpo convoca la llama.

Mi cuerpo convoca los humos.

Mi cuerpo en el desastre

como un pájaro blando.

Mi cuerpo como islas.

Mi cuerpo junto a las catedrales.

Mi cuerpo en el coral.

Aires los de mi bruma.

Fuego sobre mis aguas.

3 Ver estudio de Emoto sobre las vibraciones y la consciencia humana: Love Thyself. The Message from Water III.

$\begin{array}{llllll}\text { ISSN 0034-9631 (Impreso) } & \text { ISSN 2154-4794 (Electrónico) }\end{array}$ 


\begin{abstract}
Aguas irreversibles
en los azules de la tierra.

Mi cuerpo en plenilunio.

Mi cuerpo como las codornices.

Mi cuerpo en una pluma.

Mi cuerpo al sacrificio.

Mi cuerpo en la penunbra.

Mi cuerpo en la claridad.

Mi cuerpo ingrávido en la luz

vuestra, libre, en el arco. (156)
\end{abstract}

La cualidad rítmica del poema se da al repetir sucesivamente "Mi cuerpo" como un mantra convocatorio de todo lo que tiene el sujeto en su proximidad. Esta unión metonímica del cuerpo y lo otro, ya sea un elemento de la naturaleza (coral, agua, pluma, tierra, luna), o un ser animal (pájaro, codorniz), o un elemento cósmico (la luz, la penumbra, la claridad) deja vislumbrar en términos poéticos la concepción cuántica del universo palpitante en que todo vibra y emite ondas de energía que se interconectan y afectan mutuamente. Más específicamente, la poeta evoca las imágenes, "Aires los de mi bruma” y "Fuego sobre mis aguas", que sugieren auras energéticas emanando del cuerpo. El final del poema se extiende al ámbito cósmico donde las leyes de la gravedad newtonianas no son aplicables. Más allá del planeta, en el cosmos "ingrávido", el cuerpo ya no es partícula sino que se convierte en un "arco de luz". Partícula hecha onda, energía pura; el cuerpo no permanece atado a la gravedad sino que ahora es libre y eterno. De forma similar, las ondas o frecuencias de radio son ondas de luz que emanan y se propagan en el espacio infinitamente, llevando con ellas las voces y las historias a través del cosmos (Windows).

La obra de Morejón tiene su lado oscuro también. La poeta evoca eficazmente la tragedia de vivir en desequilibrio con nuestro medio ambiente. En el poema "Sofisma 4" la voz poética transmite los sentimientos de alienación e inquietud que atormentan a quien está en desarmonía con el mundo. lo anterior ilustra la visión física newtoniana y filosófica dualista que formula un ser humano dividido y escindido de la naturaleza:

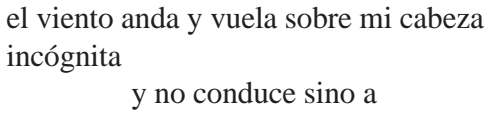

\begin{tabular}{llllll} 
Revista Iberoamericana, Vol. LXXVII, Núm. 235, Abril-Junio 2011, & 525-537 \\
\hline ISSN 0034-9631 (Impreso) & ISSN 2154-4794 (Electrónico)
\end{tabular} 


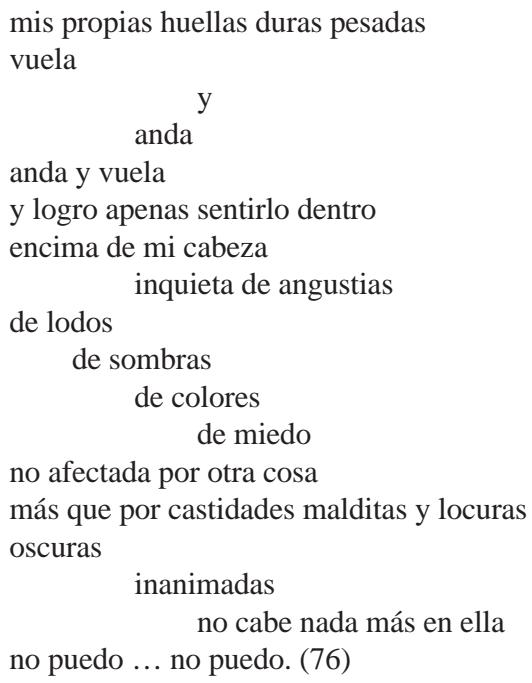

Aquí el sujeto no se integra con el viento, como en los poemas anteriores, sino que el viento "vuela sobre mi cabeza/ incógnita". La angustia se convierte en "lodos", "sombras" y "miedos" que lo desequilibran y lo rinden incapaz de actuar. En su cabeza sólo caben "castidades malditas y locuras", es decir, conflictos morales y psicológicos que terminan alienándolo y destruyendo su capacidad de poder, de poder hacer, de crear.

Mientras que en los primeros poemas analizados la poeta describe la armonía entre el sujeto y el universo, en el poema "Sofisma 4" vemos lo contrario. Lo que sucede cuando el sujeto se concibe como una entidad separada de la creación es su fracaso como ser humano. El "yo" poético de "Sofisma 4" está sumergido bajo la presión del miedo y la angustia que resulta en una vida desequilibrada, pues su resultado es el no poder; "no puedo . . . no puedo" termina el poema. La inacción, el haber perdido la habilidad de crear, y por ende el propósito de la existencia, lleva a la frustración de una vida incapaz de actuar.

El tema de la actividad y creatividad humanas está entre las aplicaciones de la física cuántica a la filosofía y la ontología. Según la cuántica, el propósito del ser humano es el de crear; considera que el sujeto es co-autor del universo y que está siempre cambiando y evolucionando en busca de un orden coherente. El universo tiene un orden, tiene leyes, pero éstas están sujetas a la incertidumbre y al azar (Prigogine 222-23). ${ }^{4}$ La esencia del ser humano, lo que lo separa de las bestias, es su creatividad,

4 Ver el postulado de la incertidumbre de Heisenberg explicado por Prigogine en Order Out of Chaos.

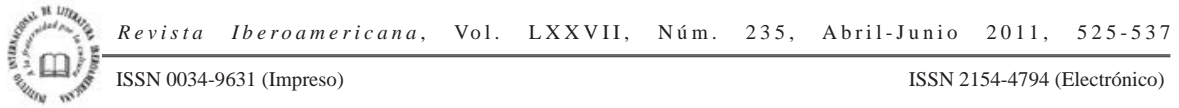


la cual conlleva tanto la libertad de acción como la responsabilidad de esa acción. El poeta es un modelo del sujeto creador, del homo ludens (y hay tantos modelos como posibles formas de descubrimiento: el científico, el filosófico, el místico, etc.). El poeta no sólo construye el objeto poético, sino que con él construye nuevas visiones del mundo que pueden afectar la forma en que nos relacionamos con él. Según Zohar y otros pensadores inspirados en la cuántica, la razón del ser humano es el descubrimiento y la creación. La creación se da por medio del diálogo interdependiente entre el sujeto y el universo (Zohar 189). Por cierto, este diálogo es evidente en la obra poética de Morejón.

Finalmente, analizaremos un poema donde la autora explora el concepto de la identidad del sujeto y la conciencia humana. Es claro que el poema "Persona" se adentra en temas de africanidad y de lo que significa ser mujer. Pero también se presta a una lectura ontológica en cuanto a la indagación sobre la conciencia, cómo se relaciona con la identidad y si la identidad es única o existe una subjetividad compartida. El poema comienza con dos preguntas: “¿Cuál de estas mujeres soy yo?/ ¿O no soy yo la que está hablando/ tras los barrotes de una ventana sin estilo/ que da a la plenitud de todos estos siglos?” (204).

Desde el comienzo se establecen los siguientes interrogantes: ¿quién soy yo?, ¿'es única mi identidad o la comparto con otros?, ¿quién es la conciencia hablante y cómo se expresa esa conciencia?, ¿es el sujeto una unidad o es una multiplicidad de entes?, y por último, ¿hasta cuándo perdura la conciencia? La visión cuántica del mundo informa estos cuestionamientos ontológicos a partir del hecho de que la conciencia es un fenómeno físico y químico basado en el funcionamiento del cerebro. Cuando el cerebro no funciona el sujeto conciente desaparece. Como sistema físico, el cerebro crea la percepción de una identidad pensante que está sujeta a las leyes moleculares cuánticas de sus procesos. La consciencia, por medio de la memoria, actúa como un hilo de unión entre todos los procesos cerebrales que toman lugar en la mente en un momento dado y crea la sensación de un sujeto unitario, de la identidad personal. Pero el sujeto sólo existe en su relación con lo que lo rodea y con los otros sujetos. Ya Ortega y Gasset había estipulado que "Yo soy yo y mis circunstancias" (45). Yo soy yo en cuanto me relaciono con otros sujetos y de esa relación surge un ser tercero, el que se establece en la relación. Sartre lo explicó bien en su obra de teatro Huis Clos (A puerta cerrada), donde los tres protagonistas conciben su identidad sólo en la relación del uno con el otro.

La física cuántica sugiere que el sujeto toma forma en cuanto es un sujeto en relación, podríamos decir que somos nuestras relaciones. Y más aún, que hay una subjetividad compartida de los sujetos entre sí y con la naturaleza. La cuántica descubre que el observador tiene un efecto físico sobre lo observado. Esto se demuestra con un experimento donde se miden los electrones. El resultado del experimento es diferente

Revista Iberoamericana, Vol. LXXVII, Núm. 235, Abril-Junio 2011, $525-537$
ISSN 2154-4794 (Electrónico) 
cuando es observado en el proceso de medirlo. El acto de ser medido interfiere con el resultado del electrón, determinándolo como partícula u onda (Zohar 25-27). Este concepto de la subjetividad compartida, o complementariedad, aparece en la filosofía con las teorías de percepción de Berkeley, que postulan la importancia de la percepción y la relación entre el observador y lo observado. ${ }^{5}$

Morejón trata este tema en el poema "Persona". La voz poética siente que su existencia está íntimamente identificada con la de otras subjetividades. El poema consiste en una serie de preguntas retóricas donde se cuestiona el concepto de una identidad fija y personal. Lo que surge como resultado es la idea del común denominador de la experiencia. La persona poética siente que es parte de todas las mujeres con las que entra en contacto, que hay en ellas algo suyo y de ella, a su vez, se concibe como parte de las otras.

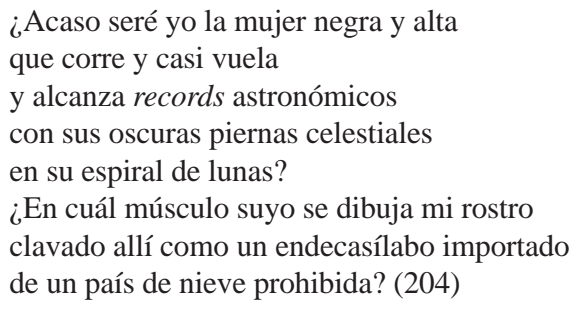

La identificación corporal de su rostro clavado en el músculo de la atleta es sólo una de muchas imágenes de subjetividad compartida. Continúa el poema con otras:

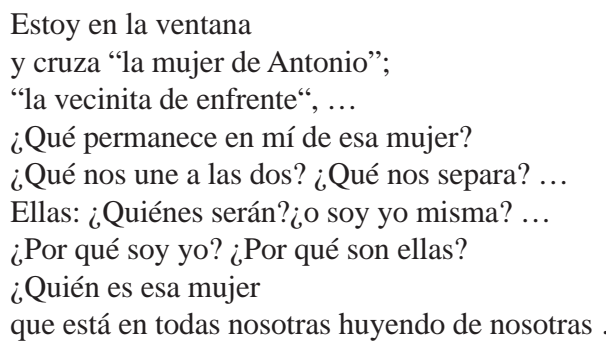

Estos cuestionamientos encuentran una respuesta en la última estrofa del poema, donde la identidad se encuentra en la armonía del sujeto con el universo. La conciencia compartida, la experiencia de ser mujer se une desde la carne y los huesos para

6 Hay varias obras del filósofo inglés del siglo xvIII, George Berkeley, donde expone su teoría del idealismo y la inmaterialidad.

ISt) 
encontrarse en los huesos de otras, en el pasado compartido y que va más allá de lo personal.

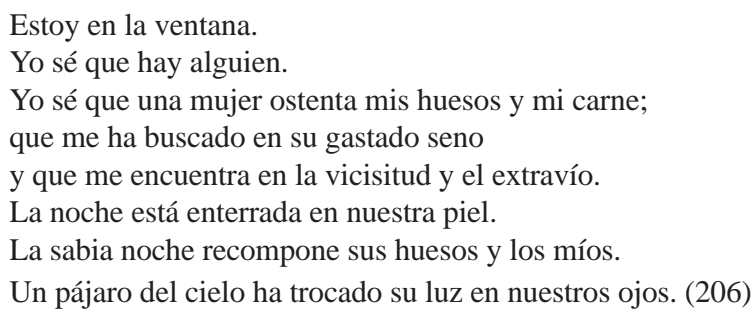

Aquí la voz poética descubre que ella y sus semejantes comparten cuerpos, pensamientos y fenómenos naturales que revelan una subjetividad interconectada. En la sabiduría de la naturaleza, "la sabia noche”, comprende que es parte de otros seres y de otros elementos. Y con este descubrimiento se "recompone”, entrando así la luz y el esclarecimiento: "Un pájaro del cielo ha trocado su luz en nuestros ojos".

Para concluir, señalaremos que los paralelos entre la física cuántica y la poesía no son únicamente conceptuales, sino que en la poesía hay técnicas y estructuras escriturales que siguen procesos mecánicos cuánticos. Ya hemos mencionado el mecanismo de la sinestesia y su efecto de fusionar los sentidos y las emociones en un todo indistinguible. Otro mecanismo compartido es el de la superposición, fenómeno que establece que las partículas subatómicas poseen la habilidad de estar en diferentes sitios al mismo tiempo (Zohar 211) y que múltiples partículas pueden ocupar el mismo lugar simultáneamente. Este potencial de multiplicidad de significados es lo que se da en la polisemia poética. Una frase poética encierra una profundidad de interpretaciones y connotaciones que también ocupan el mismo espacio y que requieren del lector para captar la polisemia contenida en la unidad de la metáfora o de la imagen. Los textos de Morejón a los cuales nos hemos referido aquí presentan ejemplos de la superposición polisémica y lo hacen dentro de un cuadro de imágenes que evoca una relación intrínseca del sujeto con sus semejantes y con la naturaleza.

En la poesía de Nancy Morejón hay una fusión simbólica, metafórica, metonímica y conceptual de la experiencia humana ante el universo que refleja la conectividad y la complementariedad del mundo cuántico. A esto se suma una perspectiva del sujeto desde su posición de mujer. Si bien el sujeto de estos poemas va más allá de sus significaciones de género para evocar una conciencia prototípica, la obra de Morejón refleja también la experiencia desde la perspectiva de la mujer, tema que no elegimos explorar aquí. Pero es pertinente señalar que es precisamente esta perspectiva femenina la que se relaciona con el proceso cuántico de engendrar la conexión y la capacidad de relación. Explica Zohar que: "there is something deeply feminine about seeing the self

Revista Iberoamericana, Vol. LXXVII, Núm. 235, Abril-Junio 2011,
ISSN 2154-4794 (Electrónico) 
a part of a quantum process, feeling 'I' and 'you' overlap” (151). Añadiríamos también que hay algo intrínsecamente femenino en el acto de crear, razón de ser del ser humano en el universo cuántico.

\section{BiBLIOGRAFÍA}

Baudelaire, Charles. Fleurs du mal. París: Gallimard, 1961.

Briggs, John, y F. David Peat. Turbulent Mirror. An Illustrated Guide to Chaos Theory and the Science of Wholeness. Nueva York: Harper \& Row, 1971.

Eliot, T.S. Four Quartets. Nueva York: Harcourt Inc., 1971.

Emoto, Masaru. The Hidden Messages in Water. David Thayne, trad. Nueva York: Pocket, 2004.

Love Thyself: The Message From Water III. Londres: Hay House, 2006.

Gilmore, Robert. Scrooge's Cryptic Carol. Visions of Energy, Time and Quantum Nature. New York: Copernicus, 1996.

Gleick, James. Chaos. Making a New Science. Nueva York: Penguin, 1987.

Greene, Brian. The Elegant Universe: Superstrings, Hidden Dimensions, and the Quest for the Ultimate Theory. Nueva York: W.W. Norton, 2003.

Hayles, N. Katherine. Chaos and Order: Complex Dynamics in Literature and Science. Chicago: U of Chicago P, 1991.

Hayles, N. Katherine. Chaos Bound: Orderly Disorder in Contemporary Literature and Science. Ithaca: Cornell UP, 1990.

Krishnamurti, Jiddu. The First and Last Freedom. New York: Harper Collins, 1995.

Morejón, Nancy. Looking Within/Mirar adentro: Selected Poems/ Peomas escogidos 1954-2000. Juanamaría Cordones-Cook, ed. Detroit: Wayne State UP, 2003.

Ortega y Gasset, José. Meditaciones del Quijote. Madrid: cátedra, 2007.

Prigogine, Ilya. Order out of Chaos. Man's New Dialogue with Nature. Nueva York: Bantam, 1984.

Sartre, Jean-Paul. Huis Clos (suivi de Les Mouches). París: Theatre, 2000.

Windows to the Universe. University for Atmospheric Research (UCAR). <http:// www.windows.ucar.edu>.

Zohar, Danah. The Quantum Self. Human Nature and Consciousness Defined by the New Physics. New York: Quill, 1990.

$\begin{array}{llllll}\text { Revista Iberoamericana, Vol. LXXVII, Núm. 235, } & \text { Abril-Junio 2011, } & \text { 525-537 } \\ \text { ISSN 0034-9631 (Impreso) } & \text { ISSN 2154-4794 (Electrónico) }\end{array}$ 
